\title{
A Study on the Relationship between Beginning Teachers' Role Stress and Career Commitment
}

\author{
Hongxia Liu* and Yinuo Liu \\ School of Management, Capital Normal University, Beijing, China, 100089 \\ ${ }^{*}$ Corresponding author
}

\begin{abstract}
Based on the questionnaires of 331 beginning teachers in primary and secondary schools, the relationship between role stress and career commitment was investigated. The study reveals that the majority of beginning teachers are under relatively large pressure and their career commitment is moderately above the medium level. Correspondingly, role ambiguity and role overload can negatively predict career commitment of beginning teachers. Therefore, primary and secondary schools should take active measures to help beginning teachers relieve their role stress, help them adapt to their role faster and better, and then improve their career commitment.
\end{abstract}

Keywords-role stress; career commitment; beginning teachers

\section{INTRODUCTION}

Work stress is one of the dominant research topics in organizational management. In the work stress study, the role stress is an important branch. Viewed from the source of individual stress, role stress shows the pressure that employees perceive because of the role ambiguity, role conflict, role overload and other factors. The so-called role stress refers to the anxiety when individual cannot achieve his or her role expectancy. Generally, the role ambiguity, role conflict, and role overload are considered to be the primary source of individual role stress. Teachers need to assume a variety of roles in their work: they are the imparters of knowledge, the solvers of puzzles, and the organizers of class activities, the psychological consultants for students, and the inheritors and implementers of educational ideas. Since each role of teachers is given great expectation, compared with other occupations, the role stress of teachers is much greater. For newly recruited teachers, it is necessary to overcome the dual transition from being educated to educating students, and from Social People to Professional. Despite the lack of work experience, beginning teachers still need to play a variety of roles well. Therefore, beginning teachers are facing greater role stress than those experienced teachers who have already been familiar with the roles in their work. If the stress cannot be effectively relieved, it would reduce beginning teachers' enthusiasm and career commitment [1], and could even lead to their leaving. The early stage of work is significant for beginning teachers' career development, and is also related to the degree of their work adaptation and the cultivation of their professional identity of being a teacher. Thus, the role stress and career commitment of beginning teachers must be taken seriously.

In the previous studies on career commitment, the main variables besides demographic variables such as gender, age, educational background, working time, and working place, include job satisfaction, job burnout, working pressure, superior's support and so on. However, the research about the impact of role stress on career commitment is rare. Through an empirical research, Bedeian \& Armenakis (1981) found that the role conflict and role ambiguity do lead to job dissatisfaction for individuals, and can even let them give up work [2]. Some studies also found that the role stress has negative impact on organizational commitment [3]. It can be inferred that excessive role stress would reduce career commitment.

What is the status of role stress and career commitment during beginning teachers' early stage of work? Is there a negative prediction between role stress and career commitment? This study will focus on these issues. The solution of these issues can not only broaden the scope of the theoretical research on role stress and career commitment, but also have positive influence on relieving beginning teachers' role stress, promoting their work adaptation, elevating their career commitment, improving their teaching quality, as well as enhancing their teaching effectiveness.

\section{METHOD}

\section{A. Sample and Procedure}

In this study, the "beginning teacher" refers to the teacher who has get Teacher Certification, and has begun teaching within one year in a primary or secondary school [4]. This study mainly adopts questionnaire investigation. A total of 410 questionnaires were issued at a training course, organized by Haidian District Board of Education and Chaoyang District Board of Education, for primary and secondary schools' beginning teachers who has been working for half a year. The investigator is responsible for reading the instruction and answering the questions the respondents has encountered during the questionnaire filling process. A total of 331 valid questionnaires were collected, 28 invalid questionnaires were eliminated because of incompleteness and answering consistency (that is, all the subjects are basically chosen the same answers), and the effectiveness rate is $80.7 \%$. The survey data show that the final sample of beginning teachers has an average age of 25.6 years $(\mathrm{SD}=2.572)$, with men accounting for $38.1 \%$, and women accounting for $87.0 \%$. Overall, $38.1 \%$ of respondents had college education background, and $61.9 \%$ of them are postgraduates. About $20.5 \%$ are married, and about $79.2 \%$ are unmarried, the others account for $0.3 \% .74 .9 \%$ of respondents have graduated within one year, $13.0 \%$ are in $1-3$ years, $5.1 \%$ are in $3-5$ years, and $6.9 \%$ are in 5 years. $55.9 \%$ of 
them are teaching at primary schools, $25.4 \%$ are at junior high schools, and $18.7 \%$ are at senior high schools.

\section{B. Measures}

The role stress scale developed by Peterson (1995) and translated by Chaoping LI and Yi ZHANG (2009) is used to measure the role stress, which includes 3 dimensions (role ambiguity, role conflict, and role overload) and 13 items [5]. The scale is revised on the basis of the former mature scale and combined with the actual situation of teachers in China. It is more suitable for the measurement of Chinese teachers groups, and was validated in subsequent studies that it has high reliability and validity as well [6]. To be more detailed, the scale contains 5 role ambiguity items (like "I (do not) have clear planned goals and objective for my job"), 3 role conflict items (like "I often get involved in situations in which there are conflicting requirements"), and 5 original role overload items (like "there is a need to reduce some parts of my role"). The scale uses a five-point scale $(1=$ strongly disagree, $5=$ strongly agree) to describe from strongly disagree to strongly agree. The five items about the role ambiguity are all reverse scored, while the eight other items are forward scored. In this study, the Cronbach $\alpha$ of the three dimensions of role stress are 0.854 , $0.690,0.702$ and 0.908 respectively.

Blau (1988)'s single-dimension career commitment scale, which is widely adopted internationally, is used to measure career commitment [7]. The scale contains 7 items. It also uses a five-point scale $(1=$ strongly disagree, $5=$ strongly agree $)$ to describe from strongly disagree to strongly agree. Four items on the "Ideal vocation for a life work" are all forward scored, while other three items on the "Would go into a different industry if paid the same" are reverse scored. In this study, the Cronbach $\alpha$ of the single-dimension career commitment scale is 0.805 .

During the research, some general demographic data such as age, gender, educational background, graduation years and teaching level were also collected and used as control variables of the study.

\section{Methods of Data Processing}

In this study, SPSS 19.0 is applied to analyze the collected data, and the mainly data analysis methods are descriptive statistical analysis and hierarchical regression analysis.

\section{RESUlTS}

The mean, standard deviation (SD), Pearson correlation coefficient and Cronbach $\alpha$ of the main variables are shown in Table 1.As is indicated by data in Table 1 , the major kinds of role stress for beginning teachers are from the role overload and role conflict: the problem of role overload is most serious $(\mathrm{M}=3.288)$; following is the role conflict $(\mathrm{M}=3.253)$; while the role ambiguity is at a relatively low level $(\mathrm{M}=2.167)$. The mean of career commitment is 3.749 , which is close to 4 , a relatively high level, which means that the career commitment of beginning teachers is moderately above the medium level.
TABLE I. THE RESULTS OF DESCRIPTIVE STATISTICS ANALYSIS AND CORRELATION ANALYSIS

\begin{tabular}{|l|c|c|c|c|c|c|}
\hline Variable & Mean & SD & $\mathbf{1}$ & $\mathbf{2}$ & $\mathbf{3}$ & $\mathbf{4}$ \\
\hline $\begin{array}{l}\text { Role } \\
\text { Conflict }\end{array}$ & 3.253 & 0.747 & $(0.69)$ & & & \\
\hline $\begin{array}{l}\text { Role } \\
\text { Ambiguity }\end{array}$ & 2.167 & 0.440 & $0.242^{* *}$ & $(0.702)$ & & \\
\hline $\begin{array}{l}\text { Role } \\
\text { Overload }\end{array}$ & 3.288 & 0.889 & $0.383^{* *}$ & $0.176^{* *}$ & $(0.908)$ & - \\
\hline $\begin{array}{l}\text { Career } \\
\text { Commitme } \\
\text {-nt }\end{array}$ & 3.749 & 0.608 & $\begin{array}{c}-198^{* *} \\
0.347^{* *}\end{array}$ & $\begin{array}{c}0.390^{* *} \\
(0.805\end{array}$ \\
\hline
\end{tabular}

${ }^{*} \mathrm{p}<0.05 ; * * \mathrm{p}<0.01$; The data in brackets are Cronbach's $\alpha$ corresponding for variables measurement.

In addition, as can be seen from the data in Table 1, the three dimensions of beginning teachers' role stress are significantly negatively correlated with career commitment, and the correlation coefficient has reached the significant level of 0.01 , which shows that the greater the role stress of beginning teachers, the lower career commitment they keep.

The hierarchical regression analysis is applied in this study. First, demographic variables are introduced into the regression equation as the first layer variables. Then the three dimensions of role stress are introduced as the second level variables into the regression equation. The purpose is to examine whether beginning teachers' career commitment would be affected by the role stress after controlling the demographic variables. The results are shown in Table 2.

TABLE II. THE RESULTS OF HIERARCHICAL REGRESSION ANALYSIS AMONG VARIABLES

\begin{tabular}{|c|c|c|}
\hline \multirow{2}{*}{ Variable } & \multicolumn{2}{|c|}{$O C(\beta)$} \\
\hline & Model 1 & Model 2 \\
\hline \multicolumn{3}{|l|}{$\begin{array}{l}\text { Demographic } \\
\text { Variables }\end{array}$} \\
\hline Age & 0.077 & 0.040 \\
\hline Gender & $-0.129^{*}$ & $-0.121^{*}$ \\
\hline $\begin{array}{l}\text { Educational } \\
\text { Background }\end{array}$ & 0.033 & 0.019 \\
\hline Marital Status & -0.126 & -0.077 \\
\hline $\begin{array}{l}\text { Teaching } \\
\text { Level }\end{array}$ & 0.035 & 0.007 \\
\hline $\begin{array}{l}\text { Graduation } \\
\text { Years }\end{array}$ & -0.067 & -0.069 \\
\hline \multicolumn{3}{|l|}{$\begin{array}{l}\text { Independent } \\
\text { Variable }\end{array}$} \\
\hline Role Conflict & 0.007 & \\
\hline $\begin{array}{l}\text { Role } \\
\text { Ambiguity }\end{array}$ & & $-0.270^{* * *}$ \\
\hline $\begin{array}{l}\text { Role } \\
\text { Overload }\end{array}$ & & $-0.329^{* * *}$ \\
\hline $\mathrm{F}$ & $3.352^{* *}$ & $12.485^{* * *}$ \\
\hline $\mathrm{R}^{2}$ & 0.058 & 0.259 \\
\hline$\Delta \mathrm{R}^{2}$ & $0.058^{* *}$ & $0.201^{* * *}$ \\
\hline
\end{tabular}

As can be seen from the Table 2, only gender can significantly negatively predict career commitment in Model 1, while other factors have no significant impact on career 
commitment. In model 2, after controlling the demographic variables, the regression of the three dimensions of role stress and career commitment revealed an increase of $20.1 \%$ in the variance, indicating that the beginning teacher's role stress can negatively predict career commitment. And the contribution of this negative prediction mainly comes from the role ambiguity and role overload, while the role conflict has no significant impact on career commitment. In other words, excessive role ambiguity and role overload will weaken the career commitment of beginning teachers.

\section{DisCUSSION}

The role stress of beginning teachers comes mainly from role overload and role conflict, but has less relationship with role ambiguity. This finding coincides with the actual situation of Chinese teachers. Under the period of education reform, the occupation "teacher" has been given multiple roles, higher expectations and more responsibilities by students, their parents and even the whole society. Yet some requirements are indeed beyond the capacity of beginning teachers, which made them difficult to adjust themselves and lead to the role overload eventually. Meanwhile, beginning teachers are always facing different role expectations at work, when trying to meet one of these expectations, it may conflict with other expectations, and thus the role conflict is created. However, teacher's career boundary is relatively clear. Although beginning teachers are inexperienced in general, they mostly graduated from normal universities, and after systematically learning they have been familiar with teachers' role cognition, work norms and their own roles. Therefore, their role is less ambiguous.

The results indicate that the career commitment of beginning teachers is moderately above the medium level, which is basically consistent with the results of Fuming XU and Congshu ZHU (2005) on the study of primary and secondary school teachers' career commitment [8]. But in terms of scoring, the career commitment of beginning teachers is slightly higher than that of Fuming XU and Congshu ZHU (2005)'s study. This is because beginning teachers, as the object of study, have just stepped into the occupational field, and they have full of enthusiasm and willingness to throw them into work compared to experienced teachers.

The three dimensions of beginning teachers' role stress are significantly negatively correlated with career commitment, which shows that the greater the role stress of beginning teachers, the lower career commitment they keep. Therefore, the primary and secondary schools should attach great importance to beginning teachers' role stress and take active measures to help them to relieve, which could positively improve their career commitment and retain beginning teachers effectively. This is consistent with the study's original inference. In addition, the hierarchical regression analysis shows that the role ambiguity and role overload can negatively predict career commitment. The influence of role conflict on career commitment of beginning teachers is not significant, mainly because the multiple roles of teachers is widely known and accepted by beginning teachers, and thus cannot be the driving force for them to give up the idea of being teachers. However, role ambiguity and role overload are easy to make beginning teachers deny teacher profession in essence and even left their job. It means that the school's efforts in clarifying beginning teachers' professional role and reducing role overload can effectively improve career commitment of beginning teachers.

\section{CONCLUSIONS AND IMPLICATIONS}

Under the conditions of this study, the main conclusions are drawn as follows: the majority of the beginning teachers are under great role stress, which mainly come from role overload and role conflict; the career commitment of beginning teachers is moderately above the medium level; the role ambiguity and role overload can negatively predict career commitment.

This study suggests that primary and secondary schools should take the following measures to improve the career commitment of beginning teachers:

First, quickly explicating the role expectations and clarifying responsibilities for beginning teachers with simple and clear ways when they are trained would avoid the role ambiguity.

Second, primary and secondary schools should endow beginning teachers' roles according to their actual situation and avoid allocating the work that simultaneously requires a variety of roles for inexperienced beginning teachers to reduce the role overload. For example, at the beginning of their career, helping them understand education in-depth and to ensure that they are completely familiar with teaching before distributing other works.

Third, through regular or irregular training and experience exchanging between experienced teachers and beginning teachers, latter teaching ability and working skills could be enhanced to help them quickly and flexibly adapt their roles.

Fourth, primary and secondary schools should keep abreast of the problems that beginning teachers encountered in role adapting, implement adaptive guidance, and provide efficient solutions timely to help them shift different roles flexibly and reduce role conflict and relieve role stress effectively.

\section{REFERENCES}

[1] Cordes Cythia L, Dougherty Thomas W, "A review and an integration of research on job burnout", Academy of Management Review, 1993, vol. 18(4), pp. 621-634.

[2] Bedeian A G, Armenakis, "A path-analytic study of the consequences of role conflict and ambiguity”, Academy of Management Journal, 1981, vol. 24(7), pp. 417-424.

[3] Morris J H, Sherman J D., "Generalizability of an organizational commitment model”, Academy of Management Journal, 1981, vol. 24(3), pp. 512-526.

[4] Xiaomin HE, "An analysis of the current situation of teachers' outflow in primary and secondary schools in rural areas and the reasons", Educational Measurement and Evaluation, 2010, Issue 11, pp. 29-32. (In Chinese)

[5] Chaoping LI, Yi ZHANG, "The effect of role stressors on physical health and mental health among Chinese teachers", Psychological Development and Education, 2009, vol. 25(1), pp. 114-119. (In Chinese)

[6] Zhonghua GAO, Chen ZHAO, "Why is it difficult to balance work and family?An analysis based on work-family boundary theory", Acta Psychologica Sinica, 2014, vol. 46(4), pp. 552-568. (In Chinese) 
[7] Blau G, "Further exploring the meaning and measurement of career commitment", Journal of Vocational Behavior, 1988, Issue 32, pp. 284297.

[8] Fuming XU, Congshu ZHU, "A study on the status and characteristics of primary and secondary school teachers' career commitment", Education Exploration, 2005, Issue 3, pp. 118-120. (In Chinese) 